$\underline{\xi}=-m$

\title{
Metformin and l-glutamine ameliorate pancreatic damage induced by chronic nicotine exposure in adult male albino rats
}

\author{
Eman Abdel-Mohsen Abdel-Aziz ${ }^{1}$, Asmaa Y. A. Hussein ${ }^{2}$, Heba A Elnoury ${ }^{1}$ \\ ${ }^{1}$ Department of Pharmacology, Faculty of Medicine, Banha University, Egypt \\ ${ }^{2}$ Department of Forensic Medicine \& Clinical Toxicology, Faculty of Medicine, Banha University, Egypt \\ *Corresponding author E-mail: asmaa.hussein@fmed.bu.edu.eg
}

\begin{abstract}
Nicotine is a major addictive component of tobacco and cigarettes. It is believed to play a major role in the development of many diseases of pancreas including induction of pancreatitis and pancreatic cancer. This study was designed to assess the ameliorative effect of metformin \& L-glutamine administered either individually or in combination on pancreatic damage induced by chronic exposure to nicotine. Fifty-six adult male albino rats were divided into 7 weight matched groups of 8 animals per each group and treated once daily for a period of 10 weeks according to the following protocol; group I (normal control): left without intervention ; they were allowed to free access to balanced diet \& distilled water for the end of the experiment, group II (metformin treated group; Met): metformin was administrated to normal rats at a dose of $(150 \mathrm{mg} / \mathrm{kg} / \mathrm{day} /$ orally); group III (glutamine group ; LG): in which L-glutamine was given to normal rats at a dose of $500 \mathrm{mg} / \mathrm{kg}$ by oral gavage); group IV (diseased non-treated group ;Nicotine) were injected subcutaneously with nicotine $(1.5 \mathrm{mg} / \mathrm{kg} /$ day after day) to induce pancreatitis; group V (Nicotine + Met), VI (Nicotine $+\mathrm{LG}) \&$ VII $($ Nicotine + Met + LG) were treated by (Nicotine + Met, Nicotine + LG \& Nicotine + Met + LG respectively) by the same doses and routs described above. At the end of the experiment the following biochemical parameters were measured (fasting blood glucose, plasma insulin level, serum amylase and lipase level, tumor necrosis factor alpha (TNF- $\alpha$ ), heat shock protein 70 (HSP70) \& reduced glutathione; GSH) to investigate the protective effect of either or both drugs on pancreas. Additionally, histopathological evaluations of pancreatic tissues were assessed. The current study documented the damaging effect of nicotine on pancreas evidenced by significant increase of (blood glucose level due to decrease in plasma insulin level, serum lipase and amylase \& TNF- $\alpha$ levels along with significant reduction of GSH in pancreatic tissue \& heat shock protein -70 . This was accompanied by histopathological alteration in pancreatic tissue. The previously mentioned parameters illustrate partial significant improvement in concomitant administration of individual or both metformin \& $\mathrm{L}$ glutamine along with nicotine. In conclusion, co- supplementation of metformin and L glutamine documented to be anti-hyperglycemic, antioxidant and antiinflammatory which can ameliorate the damaging effect of nicotine on pancreas. The combination use of both drugs produces more protective effect than each other alone.
\end{abstract}

Keywords: Biochemical; L-Glutamine; Metformin; Nicotine; Pancreatitis and Rats.

\section{Introduction}

Tobacco and cigarette smoking are extremely still popular all over the world and considered as one of the known risk factor for the development of numerous diseases as well as a leading causes of preventable death (jiang et al., 2010; greer et al., 2015). Nicotine is a significant constituent of tobacco and cigarettes, and potentially mediates the development of many pancreatic related diseases e.g., pancreatitis, diabetes and gallstone pancreatitis (dasgupta et al., 2009; Chowdhury, 2011).

The role of nicotine in the induction of pancreatic inflammation and pancreatic cancer as a result of cigarette smoking has been recognized and reported. Oxidative stress could provoke inflammation and development of pancreatitis through zymogen degranulation, granulocyte migration, tissue necrosis with increased amylase and lipase activity (Balakrishnan and Menon, 2007).

Metformin is an orally administered biguanide class medication used as glucose-reducing agent in management of type 2 diabetes mellitus (Knowler et al., 2002; Xin et al., 2018).

Glutamine is one of the 20 naturally occurring amino acids in dietary protein. Many studies have validated the effectiveness of glutamine supplementation in the reduction of intestinal injuries and improving systemic cell immunity (Gismondo et al., 1998; Todorova et al., 2010). L-glutamine (LG) possesses potent antiulcer, antioxidant, anti-bacterial, cardioprotective, anticancer, hepatoprotective, and antiapoptotic potential (Sadar et al., 2016).

This work aimed to investigating the possible ameliorative effect of metformin, L-glutamine and a combination of both on nicotine induced pancreatitis in rats. 


\section{Materials and methods}

\subsection{Drugs and chemicals}

Nicotine was supplied as a colorless liquid, metformin; L-glutamine was purchased from (Sigma Chemicals Co., U.S.A).

\subsection{Animals}

Fifty-six (56) adult male albino rats weighing 150-200 g were obtained from Experimental Animal Breeding Farm, (Helwan-Cairo). The animals caged 8 per cage in well ventilated place at room temperature. They allowed free water and standard food (pellets specific for rat feeding obtained from animal breeding farm) for 7 days for acclimatization.

The whole study was carried out in accordance with the research protocols according to the Ethics Committee of Scientific Research, Faculty of Medicine, Banha University that followed the recommendations of the National Institutes of Health Guide for Care and Use of Laboratory Animals (Publication No. 85-23, revised 1985).

\subsection{Animal grouping and treatments}

Fifty-six rats were divided into 7 weight matched groups of 8 animals each as follow:

Group I: normal control: left without intervention to measure the basic parameters; they were allowed to free access to balanced diet $\&$ distilled water for the end of the experiment.

Group II: metformin group (Met): in which metformin was administrated to normal rats at a dose of (150 mg/kg /day/ orally) according to (Akinola et al., 2012).

Group III: L glutamine group (LG): in which L-glutamine was given to normal rats $(500 \mathrm{mg} / \mathrm{kg}$ ) by oral gavage according to (Sadar et al., 2016).

Group IV: diseased non treated group (Nicotine): in which rats were given nicotine $(1.5 \mathrm{mg} / \mathrm{kg}$ body weight of nicotine by subcutaneous injection day after day for 10 weeks) according to (Hosseini, 2011) to induce pancreatitis.

Group V: nicotine +metformin (Nicotine +Met): in which nicotine \& metformin was administrated to rats at the same dosed and routs described above for 10 weeks.

Group VI: nicotine + L glutamine (Nicotine $+\mathrm{LG}$ ): L-glutamine was given to rats for 10 weeks along with nicotine at the same previously mentioned doses and routs.

Group VII: nicotine induced pancreatitis+ metformin+ L glutamine (Nicotine +Met + LG): in which rats were given metformin in combination with L-glutamine in the same manner as group V \& group VI respectively along with nicotine.

\subsection{Procedural details}

\subsubsection{At the start of experiment}

Pancreatitis was induced in rats of group IV, V, VI, VII by nicotine as previously described. Metformin, L-glutamine and a combination of both were given to rats along with nicotine in group V, VI, VII in respect.

\subsubsection{At the end of experiment}

All rats were anesthetized using 10mg/kg xylazine hydrochloride (Rhompun ${ }^{\circledR}$, Bayer, Istanbul) and $60 \mathrm{mg} / \mathrm{kg} \mathrm{ketamine}(\mathrm{Ketalar} \circledast$, Eczacibas1 Warner-Lambert, Istanbul). Then blood samples were taken from the heart by the technique described by Parasuraman et al. (2010). Representative pancreatic fragments were taken and used for both histopathological and molecular biological investigation.

To investigate the protective effect of either drug singly or in combination on exocrine and endocrine functions of pancreas the following biochemical parameters were measured; fasting blood glucose, plasma insulin level, serum amylase and lipase level, tumor necrosis factor alpha (TNF- $\alpha$ ) and estimation of shock protein 70 (HSP70) \& reduced glutathione (GSH) in pancreatic tissue homogenate. Additionally, histopathological evaluation of pancreatic tissues was assessed.

\subsection{Sampling}

\subsubsection{Preparation of blood samples}

At the end of the experimental, blood samples were rapidly collected by cardiac puncture and placed in dry sterilized labelled centrifuge tube to coagulate for $30 \mathrm{~min}$ at room temperature, then centrifuged at $3000 \mathrm{rpm}$ for $20 \mathrm{~min}\left(4^{\circ} \mathrm{C}\right)$ for separation of the serum which were kept at $-200 \mathrm{C}$ until biochemical estimation of previously mentioned biochemical parameters.

\subsubsection{Preparation of tissue homogenate \& histopathologic samples}

Immediately after animal scarification, pancreatic tissues samples were rapidly excised, divided into two parts; one part were promptly frozen and stored at $-80^{\circ} \mathrm{C}$ until preparation of tissue homogenate for assayed. Protein estimation was done by the method of Lowry et al. (1951). The second part was preserved and fixed in containers that included $10 \%$ neutral formalin solution then processed for histopathological analysis.

\subsection{Analysis:}

\subsubsection{Estimation of serum insulin by ELISA}

Serum insulin level was determined by using a commercial Dako Cytomation Kit (Glostrup, Denmark), an ELISA method was based on two MABs. Values were expressed as $\mathrm{mIU} / \mathrm{ml}$. 


\subsubsection{Measurement of serum amylase and lipase level}

Blood samples were centrifuged at $15,000 \mathrm{rpm}$ under $4^{\circ} \mathrm{C}$ and the plasma was separated by using sterile pipettes. Serum lipase and amylase activity were evaluated with a spectrophotometric technique by the Olympus AU-2700 autoanalyzer (Olympus, Hamburg, Germany) using commercial kits (MAN Company, Tehran, Iran). The results were expressed as U/I.

\subsubsection{Measurement of shock protein 70 (HSP70)}

HSP70 protein levels were determined using commercially available ELISA kits (Stress Gen Biotechnologies Corp). The concentrations of HSP70 protein were determined by comparison with a standard curve according to manufacturer's direction. The results were expressed as ng/100mg.

\subsubsection{Measurement of reduced glutathione (GSH)}

The GSH content was measured using the 5, 5'-dithiobis (2-nitrobenzoic acid)-oxidized GSH (DTNB-GSSG) reductase recycling assay for total glutathione (GSH + GSSG) as described by Tietze [13]. Briefly, tissues were lysed by $200 \mu \mathrm{L}$ of lysis buffer ( $50 \mathrm{mM}$ Tris-HCl, $1 \mathrm{mM}$ EGTA, and 1\% Triton X-257 100). The tissue lysate was deproteinized with the same volume of $10 \%$-sulfosalicylic acid. After centrifugation at $5000 \mathrm{~g}$ for $5 \mathrm{~min}$ at $4^{\circ} \mathrm{C}$, the supernatant was divided into 2 samples, 1 for GSH and 1 for GSSG measures. The amount of total GSH was determined by formation of 5-thio-2-nitrobenzoic acid converted from DTNB. GSSG was measured by the DTNBGSSG reductase recycling assay after treating GSH with 2-vinylpyridine for $1 \mathrm{~h}$ at room temperature. Total glutathione and GSSG levels were defined as the change in OD at $405 \mathrm{~nm}$ for $5 \mathrm{~min}$ at room temperature. The results were expressed as $\mu \mathrm{mol} / \mathrm{g}$.

\subsubsection{Measurement of tumor necrosis factor-alpha (TNF- $\alpha)$}

TNF- $\alpha$ levels were measured using an enzyme-linked immunosorbent assay (ELISA) with ELISA kits (Boster Biological Technology, Wuhan, China) according to the manufacturer's protocol. The ELISA microplate was read using an ELISA reader (Dynatech Laboratories, USA) with an absorbance maximum at $450 \mathrm{~nm}$. The cytokine levels were calculated after plotting the standard curves and expressed as $\mathrm{pg} / \mathrm{mL}$.

\subsubsection{Histopathologic evaluation}

For histopathological examination, the fixed pancreatic tissue samples were trimmed, dehydrated in ascending grades of alcohol, cleared in xylene and embedded in paraffin blocks, then sectioned at $4 \mu \mathrm{m}$ thickness and stained with Hematoxylin and Eosin (H\&E).

The histopathological alterations of pancreatic slices were interpreted in several sections from each group using a light microscope by an experienced single pathologist who evaluated it in a blinded manner for necro- inflammatory activity. The severity of pancreatitis was assessed by scoring (edema, Inflammation \& perivascular infiltration, Vacuolization, hemorrhages, Acinar cell necrosis) using scoring system ranging from 1- 4 (table 1) according to Arslan et al. (2015) with some modifications. Data from each animal were statistically analyzed.

Table 1: Grading of Pancreatic Sections

\begin{tabular}{|c|c|c|}
\hline Finding & Score & Description \\
\hline \multirow{6}{*}{ Edema } & 0 & None \\
\hline & 1 & Focal expansion of interlobular septate \\
\hline & 2 & Diffuse expansion of interlobular septate \\
\hline & 3 & $2+$ focal expansion of intercellular spaces \\
\hline & 4 & $2+$ diffuse expansion of intercellular spaces \\
\hline & 5 & + enlargement of the distance between cells \\
\hline \multirow{4}{*}{ Inflammation \& perivascular infiltration } & 0 & $0-1$ intralobular or perivascular leukocyte \\
\hline & 1 & $2-5$ intralobular or perivascular leukocyte \\
\hline & 3 & $12-20$ intralobular or perivascular leukocyte \\
\hline & 4 & $>20$ leukocyte \\
\hline \multirow{5}{*}{ Vacuolization } & 0 & Absent \\
\hline & 1 & Periductal $(<5 \%)$ \\
\hline & 2 & Focal $(5-20 \%)$ \\
\hline & 3 & Diffuse $(21-50 \%)$ \\
\hline & 4 & Severe $(>50 \%)$ \\
\hline \multirow{4}{*}{ Acinar cell necrosis } & 0 & Absent \\
\hline & 2 & 5-10 necrotic cells /HPF \\
\hline & 3 & $11-16$ necrotic cells $/ \mathrm{HPF}$ \\
\hline & 4 & $>16$ necrotic cells $/ \mathrm{HPF}$ \\
\hline \multirow{5}{*}{ Hemorrhage } & 0 & None \\
\hline & 1 & One area \\
\hline & 2 & Two area \\
\hline & 3 & Tree area \\
\hline & 4 & $<$ Four \\
\hline
\end{tabular}

HPF means high power field.

\subsection{Statistical analysis}

Using software (SPSS, Version 20.0 for Windows, SPSS Inc., Chicago, IL) was used for the univariate, bivariate, and stratified analyses of the data. Man-Whitney test was applied for the comparison of quantitative variables after establishing their non -normality by K-S test of normality. ANOVA test (F) and Kruskal-Wallis was used for multiple comparisons of quantitative variables for parametric and nonparametric variables. Differences were considered statistically significant at Probability (P) values $\leq .05$. 


\section{Results}

Administration of nicotine affected both exocrine and endocrine functions of pancreas in the form significant increase of blood glucose level as a result of significant decrease in plasma insulin level this was associated significant elevation of serum lipase and amylase levels. This was accompanied by histopathological changes in pancreatic tissue in the form of edema, inflammation \& perivascular infiltration, vacuolization, acinar cell necrosis and hemorrhage. These deleterious effects were explained by significant decrease of reduced glutathione with significant decrease of heat shock protein -70 and significant increase in TNF-alpha. Concomitant administration of metformin and/or L glutamine resulted in significant improvement of the previously mentioned parameters, metformin showed better results as regard to GSH level while L glutamine was significantly better as regard to plasma insulin level and serum HSP70 level elevation. Both drugs produced significant improvement of plasma glucose level and tissue TNF-alpha level similarly, while fasting blood glucose level and plasma insulin level were normalized on combination of the two tested drugs. Finally, the best results were obtained on combination of both drugs (table 2, 3 \&4; fig. 1).

Table 2: Effect of Metformin and/or L Glutamine on Blood Glucose Level (Mg/Dl), Serum Insulin (Miu/Ml), Serum Amylase (U L) \& Serum Lipase (U L)

\begin{tabular}{llll}
\hline & FBG & S. insulin & Serum amylase \\
\hline normal control & $102.88 \pm 13.02$ & $50 \pm 1.6$ & $472.38 \pm 36.12$ \\
metformin group (Met) & $102.13 \pm 12.31$ & $53 \pm 1.1$ & $474.5 \pm 28.12$ \\
L glutamine group (LG) & $96.75 \pm 14.81$ & $51 \pm 1.4$ & $474.25 \pm 29.11$ \\
Nicotine group & $226.38 \pm 22.29^{\text {a,b,c }}$ & $25.51 \pm 2.1^{\text {a,b,c }}$ & $896.75 \pm 47.25^{\text {a,b,c }}$ \\
Nicotine +Met & $173.88 \pm 7.57^{\text {abcd }}$ & $31.82 \pm 1.9^{\text {a,b,c,d }}$ & $716.63 \pm 50.89^{\text {a,b,c,d }}$ \\
Nicotine +LG & $168.88 \pm 9.57^{\text {abcd }}$ & $39.45 \pm 2.4^{\text {a,b,c,d,e }}$ & $698.5 \pm 50.07^{\text {ab, }, \mathrm{c}, \mathrm{d}}$ \\
Nicotine + Met +LG & $100.25 \pm 13.73^{\text {def }}$ & $49.64 \pm 1.6^{\text {d,e,f }}$ & $51.88 \pm 5.19^{\text {a,b,c }}$ \\
\hline
\end{tabular}

Table 3: Effect of Metformin and/or L Glutamine on Tissue Level of GSH (Nmol/Mg), TNF-Alpha (Pg/Ml) and Tissue Level of HSP-70(Ng/100mg)

\begin{tabular}{llll}
\hline & GSH & TNF-alpha & HSP-70 \\
\hline normal control & $54.12 \pm 0.9$ & $3.75 \pm 1.67$ & $9.31 \pm 2.4$ \\
metformin group (Met) & $53.11 \pm 0.6$ & $4.38 \pm 1.41$ & $8.68 \pm 1.3$ \\
L glutamine group (LG) & $55.33 \pm 0.8$ & $4.0 \pm 1.60$ & $10.1 \pm 2.1$ \\
Nicotine group & $25.59 \pm 1.2^{\text {a,b,c }}$ & $168.5 \pm 16.33^{\text {a,b,c }}$ & $5.68 \pm 1.3^{\text {a,b,c }}$ \\
Nicotine+Met & $38.41 \pm 0.16^{\text {a,b,c,d,e }}$ & $34.88 \pm 5.89^{\text {a,b,c,d }}$ & $23.93 \pm 2.5^{\text {a,b,c,d }}$ \\
Nicotine +LG & $32.51 \pm 0.11^{\text {a,b,c,d }}$ & $20.63 \pm 4.57^{\text {a,b,c,d,e }}$ & $30.11 \pm 3.5^{\text {a,b,c,d,e }}$ \\
Nicotine + Met +LG & $45.31 \pm 0.21^{\text {a,b,c,d,e,f }}$ & $54.5 \pm 9.74^{\text {a,b,c,d,e,f }}$ & $42.11 \pm 3.4^{\text {a,b,c,de.f }}$ \\
\hline
\end{tabular}

Nicotine + Met + LG

Table 4: Effect of Metformin and/or L- Glutamine on Pancreatic Histopathological Finding among the Studied Groups

\begin{tabular}{|c|c|c|c|c|c|c|c|}
\hline & $\begin{array}{l}\text { Control Median } \\
\text { (IQR) }\end{array}$ & $\begin{array}{l}\text { Metformin } \\
\text { (Met) Median } \\
\text { (IQR) }\end{array}$ & $\begin{array}{l}\text { L-glutamine } \\
\text { (LG) Median } \\
\text { (IQR) }\end{array}$ & $\begin{array}{l}\text { Nicotine } \\
\text { Median } \\
\text { (IQR) }\end{array}$ & $\begin{array}{l}\text { Nicotine + } \\
\text { Met Median } \\
(\mathrm{IQR})\end{array}$ & $\begin{array}{l}\text { Nicotine + LG } \\
\text { Median (IQR) }\end{array}$ & $\begin{array}{l}\text { Nicotine + Met+ } \\
\text { LG Median (IQR) }\end{array}$ \\
\hline edema & $0(0-0)$ & $0(0-0)$ & $0(0-0)$ & $5^{a b c}(4-5)$ & $3^{\text {abcd }}(2-3)$ & $2^{\text {abcd }}(2-2.75)$ & $1^{\text {abcdef }}(1-1.75)$ \\
\hline Vacuolization & $0(0-0)$ & $0(0-0)$ & $0(0-0)$ & $4^{a b c}(3-4)$ & $3^{\text {abcd }}(2-3)$ & $2^{\text {abcde }}(2-2)$ & $1^{\text {abcdef }}(0-1)$ \\
\hline Necrosis & $0(0-0)$ & $0(0-0)$ & $0(0-0)$ & $4^{a b c}(4-4)$ & $2.5^{\text {abcd }}(2-3)$ & $2^{\text {abcd }}(2-2.75)$ & $0^{\text {def }}(0-1)$ \\
\hline Haemorrhage & $0(0-0)$ & $0(0-0)$ & $0(0-0)$ & $4^{a b c}(3-4)$ & $2.5^{\text {abcd }}(2-3)$ & $2^{\text {abcd }}(2-3)$ & $0^{\operatorname{def}}(0-0.75)$ \\
\hline
\end{tabular}

$\mathrm{a} \rightarrow$ Significant versus control group; $\mathrm{b} \rightarrow$ Significant versus Metformin group; $\mathrm{c} \rightarrow$ Significant versus L- glutamine group; $\rightarrow$ Significant versus Nicotine group; $\rightarrow$ Significant versus Nicotine + Metformin group (group V); $\rightarrow$ Significant versus Nicotine+ L-glutamine group
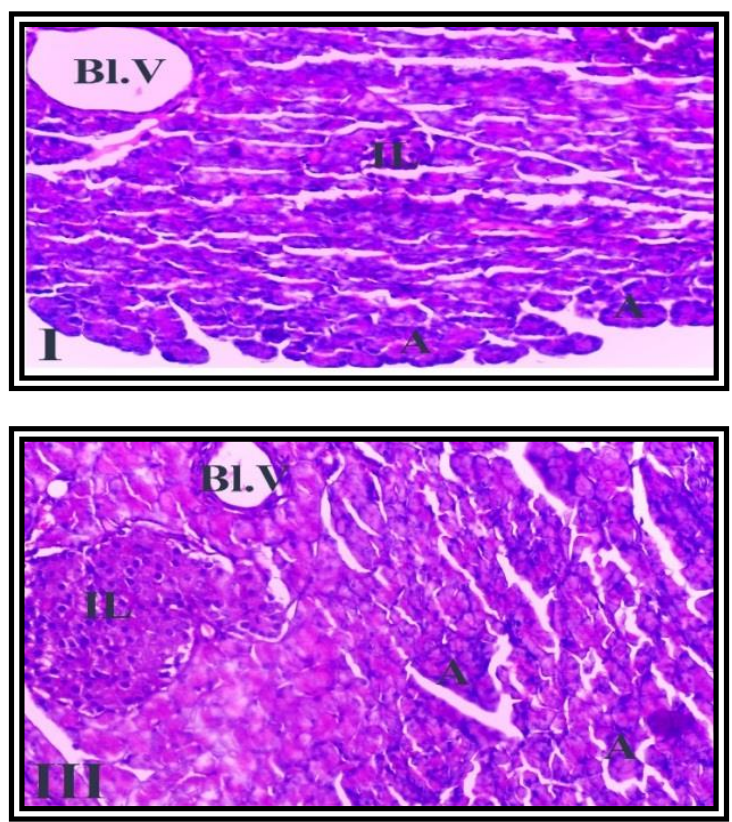
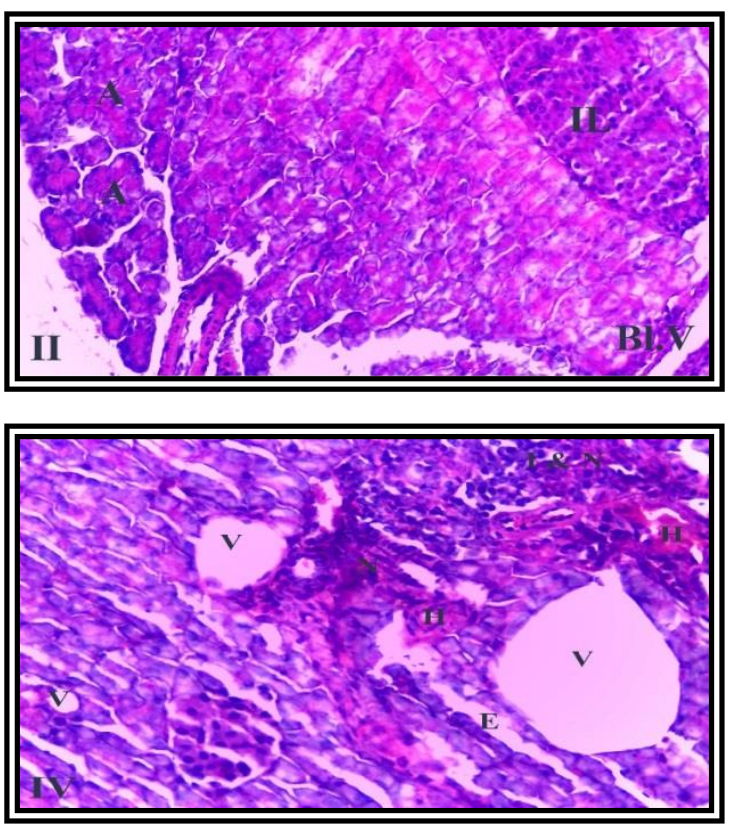

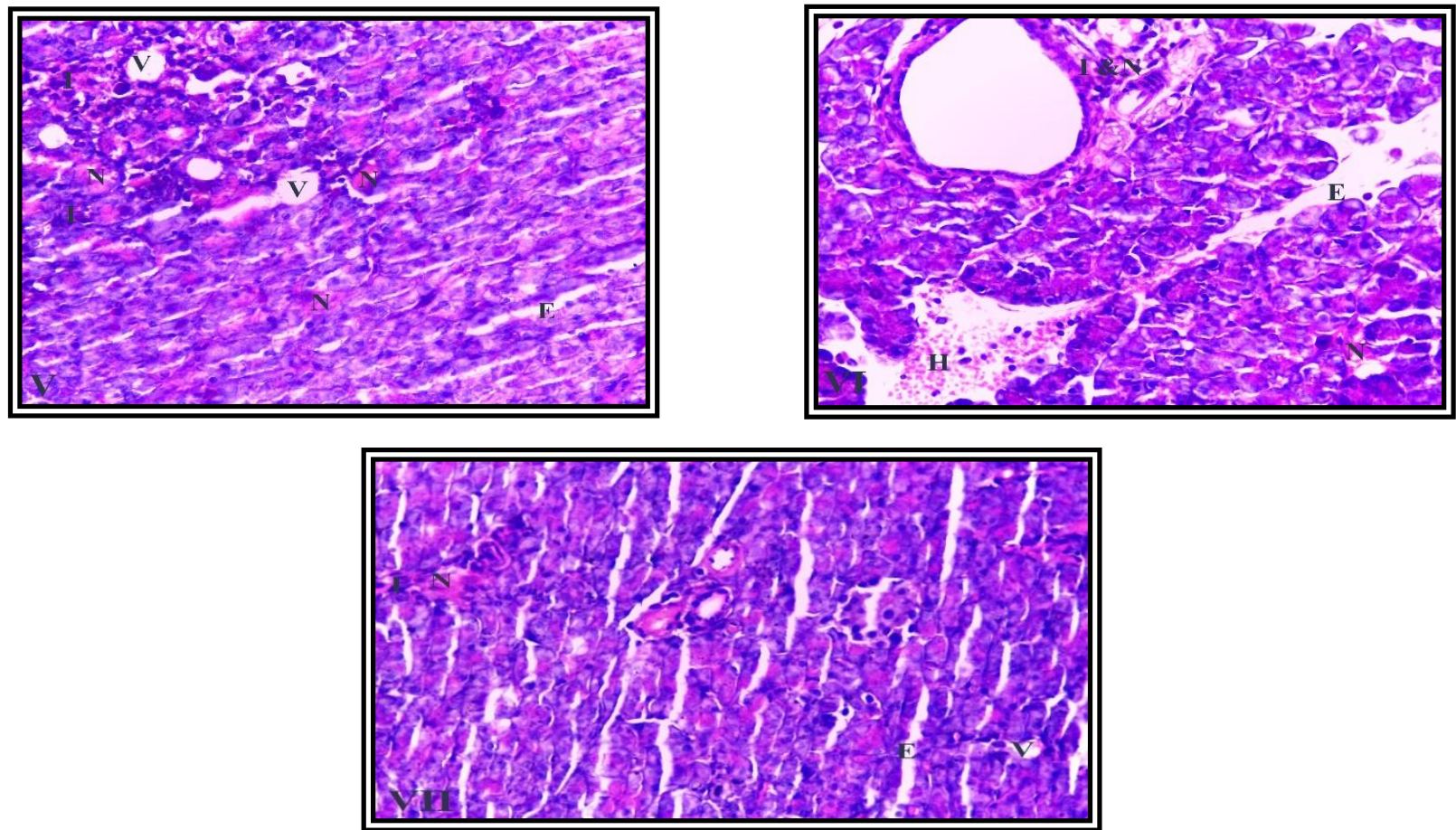

Fig. 1: Photomicrograph Sections of Pancreatic Tissues of the Studied Rats Demonstrated Ameliorating Effect of Metformin and / or L Glutamine on Histopathological Changes of Pancreatic Tissues in Rats Injected with Nicotine. All [Hematoxylin and Eosin (H\& E) X 400], Histopathological Findings as Follows:

Fig. (I, II \&III): pancreatic sections of rats in group I (control group), group II (metformin group) \& group III (L glutamine group) reveal normal architectures of pancreatic tissues in form of lobules separated by connective tissue septa and consisted of triangular acinar cells (A) with darkly stained basal nuclei and pink cytoplasm. Pancreatic islets of Langerhans (IL) observed as clusters of cells.

Fig. (IV): pancreatic a section of group IV (nicotine treated rats) showing marked interstitial edema (E) in between pancreatic acini, inflammatory cell infiltrates (I), cytoplasmic vacuolation (V), Hemorrhage (H) \& necrosis $(\mathrm{N})$.

Fig. (V, VI, \&VII): pancreatic sections of rats in group V (nicotine+ metformin), group VI (nicotine +L glutamine) \& group VII (nicotine+ metformin $+\mathrm{L}$ glutamine group) demonstrating ameliorating effect of metformin and/or L glutamine on histopathological changes of pancreatic tissues in concomitant injection with nicotine with better improvement observed in sections from group VII (nicotine+ metformin $+\mathrm{L}$ glutamine group) which illustrate minimal changes (image; VII).

\section{Discussion}

It is well recognized that nicotine has an important role in induction of pancreatitis as a component of cigarette smoking (Chowdhury, 2011).

In this work administration of nicotine for ten weeks resulted in pancreatic injury that involved exocrine function of pancreas manifested by increased serum levels of lipase and amylase enzymes as well as the endocrine function was affected revealed by decreased serum level of insulin these results were associated with inflammation and a state of oxidative stress manifested by increase chronic inflammatory mediators namely tumor necrosis factor $\alpha$ and marked reduction of natural antioxidant namely GSH in pancreatic tissue homogenates. This is in line with many studies suggesting that cigarette smoking can be a cause for development of both acute pancreatitis (Sadr-Azodi et al., 2012; Yuhara et al., 2014) and chronic pancreatitis (Law et al., 2010; Alsamarrai et al., 2014). These finding could be explained by the fact that nicotine can induce pancreatic injury partly through oxidative stress (Chowdhury and Walker, 2008) as well as disruption in anti-oxidant mechanism by enhancing Reactive Oxygen Species (ROS) production and thereby decreases antioxidant level causing per oxidative tissue damages (Ramesh et al., 2007) ; this was manifested in this work by reduction of reduced glutathione tissue level. The role of free radicals as a causative factor for inflammation was demonstrated by Connor and Grisham (1996) who showed that reactive oxygen metabolites may also initiate and/or amplify inflammation via up-regulation of several different genes involved in the inflammatory response, such as those that code for pro-inflammatory cytokines and adhesion molecules. The previously mentioned mechanisms may explain the elevation of plasma levels of pro-inflammatory parameters namely tumor necrosis factor-alpha in this work. Heat shock proteins (Hsps), also known as stress proteins and molecular chaperones, play a central role in protecting cellular homeostatic processes from environmental and physiologic insult by preserving the structure of normal proteins and repairing or removing damaged ones (Gerner et al., 1975).

In this work chronic nicotine administration resulted in decreased serum level of HSP70 this can contribute in explanation of the deterioration occurred in pancreatic functions. Decreased plasma insulin level in this work after chronic nicotine administration was in line with Yoshikawa et al. (2005) who cited that exposure to nicotine concentrations above $1 \mu \mathrm{mol} / \mathrm{L}$ inhibits insulin secretion in isolated human islet cells, this toxic influence of nicotine on insulin-secreting $\beta$ cells may be attributed to the presence of neuronal nicotinic receptors sensitive to nicotine in pancreatic cells.

In the current study concomitant administration of metformin along with nicotine resulted in improvement of all tested parameters. Metformin has antihyperglycemic effect through increase tissue insulin sensitivity due to increase expression of insulin receptors and tyrosine kinase enzyme as well as inhibition of hepatic glycogenolysis (Viollet et al., 2012), this can explain metformin improving effect on fasting blood glucose level. In addition, metformin has a unique antioxidant effect mediated by inhibition of mitochondrial oxidation through inhibition of mitochondrial respiratory chain complex (Diniz Vilela al., 2016). This effect was manifested in this work by significant improving of tissue level of reduced glutathione. The unique decrease in free radical synthesis explains the improvement of parame- 
ters related to free radical mediated inflammation namely TNF- $\alpha$. The powerful antioxidant and anti-inflammatory activity of metformin explain its ability in improvement of pancreatic exocrine and endocrine functions.

Glutamine is one of the 20 naturally occurring amino acids in dietary protein. Under normal conditions, glutamine serves as a main energy metabolism fuel for intestinal and renal enterocytes. Moreover, it was recognized that glutamine supplementation in the reduction of intestinal injuries and improving systemic cell immunity (Chai \& Sheng.2008). It is an important precursor for the synthesis of glutathione, which is a non-enzymatic antioxidant. It also plays a vital role in glutathione metabolism as well as maintenance of the cellular redox potential during elevated cellular oxidative stress (Kandhare et al., 2015). This is in this is in accordance with our results concerning with glutamine antioxidant effect which was manifested by significant improvement of reduced glutathione tissue level. Additionally, Singleton et al. (2007) suggested that the protective effect of L glutamine supplementation may be directly related to its ability of increasing expression of HSPs. This is in agreement with our results where glutamine resulted in increasing plasma insulin level with subsequent decrease in fasting blood glucose level, this could be explained by glutamine effect on glucagon like peptide-1 (Samocha-Bonet et al., 2014) as well as its ability of improving insulin action and signaling, with increased muscle glucose uptake as reported by Abboudet al. (2019).

\section{Conclusions}

In conclusion, within the dose limits used in this study, oral metformin and L glutamine supplement proved to be antihyperglycemic, antioxidant and anti-inflammatory. We may postulate that either, metformin or L glutamine can protect against nicotine induced pancreatic damage and a combination of both tested drugs produces more powerful effect than each other alone.

\section{Declaration of interest}

The authors report no conflicts of interest. The authors alone are responsible for the content and writing of this paper.

\section{References}

[1] Abboud KY, Reis SK, Martelli ME, Zordão OP, Tannihão F, de Souza AZZ, Assalin HB, Guadagnini D, Rocha GZ, Saad MJA \& Prada PO (2019). Oral Glutamine Supplementation Reduces Obesity, Pro-Inflammatory Markers, and Improves Insulin Sensitivity in DIO Wistar Rats and Reduces Waist Circumference in Overweight and Obese Humans. Nutrients.11(3), 536. https://doi.org/10.3390/nu11030536.

[2] Akinola O, Gabriel M, Suleiman A \& Olorunsogbon F (2012). Treatment of Alloxan-Induced Diabetic Rats with Metformin or Glitazones is Associated with Amelioration of Hyperglycaemia and Neuroprotection. The Open Diabetes Journal. 5(1), 8-12. https://doi.org/10.2174/1876524601205010008

[3] Alsamarrai A, Das SL, Windsor JA \& Petrov MS (2014). Factors that affect risk for pancreatic disease in the general population: A systematic review and meta-analysis of prospective cohort studies. Clin Gastroenterol Hepatol. 12(10), 1635-1644.e5. https://doi.org/10.1016/i.cgh.2014.01.038

[4] Arslan S, Okur MH, Zeytun H, Basuguy E, Ibiloglu I, Turkoglu A, Bozdag Z, Kaplan I \& Uluca U(2015). A new experimental rat model of pancreatitis using Ecballium elaterium. Int J Surg. (Pt A), 160-164. https://doi.org/10.1016/j.ijsu.2015.09.067.

[5] Balakrishnan A \& Menon VP (2007). Protective effect of hesperidin on nicotine induced toxicity in rats. Indian J Exp Biol. 45 (2), 194-202.

[6] Carvalho C, Correia S, Santos MS, Seiça R, Oliveira CR and Moreira PI (2008). Metformin promotes isolated rat liver mitochondria impairment. Mol Cell Biochem. 308(1-2), 75-83. https://doi.org/10.1007/s11010-007-9614-3.

[7] Chai J \& Sheng Z (2008). A brief account of prevention and treatment of infection in burn patients. Zhonghua Shao Shang Za Zhi.24 (2) ,84-86.

[8] Chowdhury P \& Walker A (2008). A cell-based approach to study changes in the pancreas following nicotine exposure in an animal model of injury. Langenbecks Arch Surg. 393(4), 547-555. https://doi.org/10.1007/s00423-007-0267-1.

[9] Chowdhury P (2011). Parimal Chowdhury's work on smoking related pancreatic disorders. World J Gastrointest Pathophysiol. 2 (3), 57-60. https://doi.org/10.4291/wigp.v2.i3.57.

[10] Connor EM \& Gresham MB (1996). Inflammation, free radicals and antioxidants. Nutrition. 12(4),274-277. https://doi.org/10.1016/S08999007(96)00000-8

[11] Dasgupta P, Rizwani W, Pillai S, Kinkade R, Kovacs M, Rastogi S , Banerjee S, Carless M, Kim E, Coppola D, Haura E, \& Chellappan S. (2009). Nicotine induces cell proliferation, invasion and epithelia-lmesenchymal transition in a variety of human cancer cell lines. Intl J Cancer.124 (1), 36-45. https://doi.org/10.1002/ijc.23894.

[12] Diniz Vilela D, Gomes Peixoto L, Teixeira RR, Belele Baptista N, Carvalho Caixeta D, Vieira de Souza A, Machado HL, Pereira MN, SabinoSilva R, Espindola FS (2016). The Role of Metformin in Controlling Oxidative Stress in Muscle of Diabetic Rats. Oxid Med Cell Longev. 2016:6978625. https://doi.org/10.1155/2016/6978625.

[13] Gerner EW \& Schneider MJ (1975). Induced thermal resistance in HeLa cells. Nature. 256(5517), 500-502. https://doi.org/10.1038/256500a0.

[14] Gismondo M, Drago L, Fassina M, Vaghi I, Abbiati R \& Grossi E (1998). Immunostimulating effect of oral glutamine. Dig Dis Sci.43(8),17521754. https://doi.org/10.1023/A:1018883603429.

[15] Greer JB, Thrower E \& Yadav D (2015). Epidemiologic and mechanistic associations between smoking and pancreatitis. Curr Treat Options Gastroenterol. 13(3), 332-346. https://doi.org/10.1007/s11938-015-0056-9.

[16] Hosseini E (2011). The effect of nicotine on the serum level of insulin in adult male Wistar rats. J Cell Animal Biol. 5 (10), $215-218$.

[17] Jiang J, Liu B, sitas F, Li J, Zeng X, Han W, Zou X, Wu Y \& Zhao P (2010). Smoking attributable deaths and potential years of life lost from a large, representative study in China. Tob Control. 19 (1), 7-12. https://doi.org/10.1136/tc.2009.031245.

[18] Kandhare AD, Bodhankar SL, Mohan V \& Thakurdesai PA (2015). Prophylactic efficacy and possible mechanisms of oligosaccharides based standardized fenugreek seed extract on high-fat diet-induced insulin resistance in C57BL/6 mice. J App Pharma Sci. 5(3), 035-045. https://doi.org/10.7324/JAPS.2015.50307.

[19] Kelly B, Tannahill GM, Murphy MP, and O’Neill LAJ (2015). Metformin inhibits the production of reactive oxygen species from NADH: ubiquinone oxidoreductase to limit induction of interleukin-1 $\beta$ (IL-1 $\beta$ ) and boosts interleukin-10 (IL-10) in lipopolysaccharide (LPS)-activated macrophages. J Biol Chem. 290 (33), 20348-20359. https://doi.org/10.1074/jbc.M115.662114.

[20] Knowler WC, Barrett-Connor E, Fowler SE, Hamman RF, Lachin JM, Walker EA \& Nathan, DM (2002). Reduction in the incidence of type 2 diabetes with lifestyle intervention or metformin. N Engl J Med. 346(6), 393-403. https://doi.org/10.1056/NEJMoa012512.

[21] Law R, Parsi M, Lopez R, Zuccaro G \& Stevens T (2010). Cigarette smoking is independently associated with chronic pancreatitis. Pancreatology. 10(1), 54-59. https://doi.org/10.1159/000225927.

[22] LOWRY OH, ROSEBROUGH NJ, FARR AL \& RANDALL RJ (1951). Protein measurement with the Folin phenol reagent. J Biol Chem.193(1), 265-275.

[23] Parasuraman S, Raveendran R \& Kesavan R (2010). Blood sample collection in small laboratory animals. J Pharmacol Pharmacother. 1(2),87-93. https://doi.org/10.4103/0976-500X.72350. 
[24] Ramesh T, Mahesh Ramalingam M \& Mohideen HBV(2007). Effect of Sesbania grandiflora on lung antioxidant defense system in cigarette smoke exposed rats. Int J Biol Chem. 1(3), 141-148. https://doi.org/10.3923/ijbc.2007.141.148.

[25] Sadar S, Kaspate D \& Vyawahare N (2016). Protective effect of L-glutamine against diabetes-induced nephropathy in experimental animal: Role of KIM-1, NGAL, TGF- $\beta 1$, and collagen-1. Ren Fail. 38 (9), 1483-1495. https://doi.org/10.1080/0886022X.2016.1227918.

[26] Sadr-Azodi O, Andrén-Sandberg Å, Orsini N \& Wolk A(2012). Cigarette smoking, smoking cessation and acute pancreatitis: A prospective population based study. Gut. 61(2), 262-267. https://doi.org/10.1136/gutjnl-2011-300566.

[27] Samocha-Bonet D, Chisholm DJ, Gribble FM, Coster AC, Carpenter KH, Jones GR, Holst JJ \& Greenfield JR (2014). Glycemic effects and safety of L-Glutamine supplementation with or without sitagliptin in type 2 diabetes patients-a randomized study. PLoS One. 9(11), e113366. https://doi.org/10.1371/journal.pone.0113366.

[28] Singleton KD \& Wischmeyer PE (2007). Glutamine protection against sepsis and lung injury is dependent on heat shock protein 70 expression. Is J Regul Integr Comp Physiol. 292(5), R1839-1845? https://doi.org/10.1152/ajpregu.00755.2006.

[29] Tietze F (1969). Enzymic method for quantitative determination of nanogram amounts of total and oxidized glutathione: applications to mammalian blood and other tissues. Anal Biochem. 27(3), 502-522. https://doi.org/10.1016/0003-2697(69)90064-5.

[30] Todorova VK, Kaufmann Y, Hennings L \& Klimberg VS (2010). Oral glutamine protects against acute doxorubicin-induced cardiotoxicity of tumor-bearing rats. J Nutr.140 (1), 44-48. https://doi.org/10.3945/jn.109.113415.

[31] Vinothkumar KR, Zhu J and Hirst J (2014). Architecture of mammalian respiratory complex I. Nature. 515 (7525), 80-84. https://doi.org/10.1038/nature13686.

[32] Viollet B, Guiga B, Sanz Garcia N, Leclerc J, Foretz M \& Andreelli F (2012).Cellular and molecular mechanisms of metformin: an overview.Clin Sci (Lond). 122(6), 253-270. https://doi.org/10.1042/CS20110386.

[33] Xin W, Fang L, Fang Q, Zheng X and Huang P (2018). Effects of metformin on survival outcomes of pancreatic cancer patients with diabetes: A meta-analysis. Mol Clin Oncol. 28(3),483-488. https://doi.org/10.3892/mco.2017.1541.

[34] Yoshikawa H, Hellström-Lindahl E \& Grill V (2005). Evidence for functional nicotinic receptors on pancreatic $\beta$ cells. Metabolism. 54(2), 247254. https://doi.org/10.1016/j.metabol.2004.08.020

[35] Yuhara H, Ogawa M, Kawaguchi Y, Igarashi M\& Mine T (2014). Smoking and risk for acute pancreatitis: A systematic review and meta-analysis. Pancreas.43 (8), 1201-1207. https://doi.org/10.1097/MPA.0000000000000176. 